\title{
Assessment of Student Learning Outcomes and ABET Accreditation: A Pi- lot Study of Fourth-Year Engineering Students using Longitudinal Concept Maps
}

\section{Dr. Sean Ferguson, University of Virginia}

Sean Ferguson is a Lecturer in the Department of Engineering and Society at UVA since 2014. He specializes in sustainable technology and policy making from a background in Science and Technology Studies from Rensselaer Polytechnic Institute, working on energy and environmental policy in New York State, and a former life in cellular biology.

\section{Dr. Rider W. Foley, University of Virginia}

Dr. Rider W. Foley is an assistant professor in the science, technology \& society program in the Department of Engineering and Society at the University of Virginia. He is the principal investigator at University of Virginia on the '4C Project' on Cultivating Cultures of Ethical STEM education with colleagues from Notre Dame, Xavier University and St. Mary's College. He is also the co-leader of the 'Nano and the City' thematic research cluster for the Center for Nanotechnology in Society at Arizona State University. Rider is a Research Collaborator with the Sustainability Science Education program at the Biodesign Institute. His research focuses on wicked problems that arise at the intersection of society and technology. Rider holds a Ph.D. in Sustainability from Arizona State University, and a Master's degree in Environmental Management from Harvard University and a Bachelor's degree in Environmental Science from University of New Hampshire. Before earning his doctorate, he has worked for a decade in consulting and emergency response for Triumvirate Environmental Inc. 
Assessment of Student Learning Outcomes and ABET Accreditation: A pilot study of $4^{\text {th }}$ year engineering students using concept maps 


\section{Assessment of Student Learning Outcomes and ABET Accreditation: A pilot study of $4^{\text {th }}$ year engineering students using concept maps}

In the 1980s a series events - a chemical gas release in Bhopal, the characterization of asbestos as carcinogenic, and the Challenger explosion-forced professional engineers to reflect on their role in society and their ethical responsibilities for humans and the environment ${ }^{1}$. After a decade of producing accreditation requirements ABET responded to a confluence of pressures, issuing Engineering Criteria 2000 (EC2000) that broadened the scope of learning outcomes and ceded assessment practices to educators and school administrators. Engineering education institutions drew upon expertise from ethics, history of technology, science \& technology studies (STS), philosophy, and professional practitioners to develop new curriculums in response to these requirements. Engineering schools also engaged in efforts to identify and gather evidence to report on periodic ABET evaluations and provide benchmarks against which continuous improvement could be illustrated $^{2}$. Yet, there remained considerable question about what type of evidence should be collected by each educational institution and whether the data gathered sufficiently represent attainment of the non-technical ABET EC2000 criteria for which no easily quantified 'right' answer exists $^{3}$.

ABET accreditation requirements are again under review and past debates are resurfacing between stakeholders that demand criteria be simplified or some removed. Others seek to expand upon and add greater granularity to the non-technical criteria ${ }^{4}$. Part of the justification for eliminating and/or streamlining the ABET EC2000 criteria is that educational institutions are struggling to provide valid evidence that is representative of non-technical criteria in a manner that does not require laborintensive assessment techniques. ABET suggests many options, but does not link best practices to assessment examples already developed, novel attempts that have been compared and iteratively improved upon, or failed experiments that should be avoided ${ }^{5}$. Educators, consultants, and program administrators have provided myriad assessment methodologies, yet there remains no consensus about what are transferable best practices ${ }^{3,6}$.

The goal of this paper is to share the results of an exploratory study using concept maps as an assessment technique for Criteria 3 and 5 set forth by EC2000. Concept maps were used to assess baseline student knowledge at the start of a course against a post-test to ascertain the knowledge acquired during a year-long Science, Technology and Society sequence required for $4^{\text {th }}$ year engineering students at the University of Virginia. This research addresses the challenge of evaluating knowledge acquisition in an interdisciplinary environment and where no formal 'correct' answer exists through adapting a well-documented method to gather and analyze student level data against ABET EC2000 criteria requirements - all while keeping time and resource considerations in mind. Student-participants completed three concept maps at different points in the academic year. The results offer insights regarding differences between instructors, changes in student-outcomes over time, and demonstrate a means to evaluate how student learning aligns with non-technical criteria. This paper offers an initial evaluation of the strengths and limitations of the methodology, comparisons to past use of concept maps in education assessment, and offers next steps for this research. 


\subsection{Research Design}

One of the challenging aspects of any assessment is determining what are sufficient direct and indirect measures and how to incorporate both into a continuous improvement plan (CIP) ${ }^{7}$. Direct measures such as tests and problem sets, which are used in most courses, coupled with indirect surveys can lead to a "death by assessment" if they are not connected to a CIP focused on programmatic goals or if the measures are not sufficiently robust ${ }^{8}$. The challenge is to find a balance between credible assessment and efficient deployment and analysis.

This project explores the well-documented methodology of concept maps used in more than 500 prior educational studies ${ }^{9}$ can be repurposed to gather and analyze student learning with the goal of large-scale and efficient assessment in mind. This research seeks to address:

1. How can semi-structured instruments, such as concept maps, provide evidence for knowledge acquisition in non-technical fields where 'perfect' answers are not the desired student-outcome, such as understanding and recognition for social context?

2. Can the results from concept mapping activities be linked to ABET criteria and considered as a means for institutional assessment? How does timing and instructions affect the concept mapping activity?

These questions lead to an exploration of the utility of concept maps to gather evidence of knowledge acquisition in non-technical dimensions of engineering education associated with Criteria 3 and 5 and methodological pitfalls that can influence mapping and evaluation of the results.

\subsection{Concept Mapping: Justification and Method}

Concept maps capture expressions of connected ideas in a visual layout. They depict a web of ideas (nodes) and lines described by linking phrases or clauses (connections). They can be directed with a given central term, phrase, or object. Concept mapping techniques are flexible and adaptable to capture expressions of diverse topics and can be coupled with complementary methods to augment the evaluation. Nesbit and Adesope ${ }^{9}$ conducted a meta-analysis of hundreds of other use-cases in educational research to note the increasing use of concept mapping across many disciplines as both knowledge documentation and educational tool.

Derbentseva et al. ${ }^{11}$ present evidence that concept mapping offer students a means to convey how a, "dynamic relationship between two concepts reflects and emphasizes the propagation of change in these concepts. It shows how change in quantity, quality, or state in one concept causes change in quantity, quality, or state of the other concept in a proposition. In other words, a dynamic relationship reflects the functional interdependency of the two concepts involved." Concept maps serve as a strategically useful tool for allowing student participants to freely integrate complex ideas from multiple experiences and courses to a given thematic framework. Kinchin ${ }^{12}$ provides critical analysis of concept mapping practices from several decades worth of publications on concept maps and gives recommendations on structuring the mapping activity and coding practices derived. 
Concept maps offer a means to capture pre-post learning outcomes, are flexible and adaptable for deployment in diverse settings, and can be used in situations where there is no single correct answer.

The core goal of this project sought to evaluate students' knowledge acquisition and integration ${ }^{13}$ with an emphasis on conceptual understanding over a period of time ${ }^{14}$. The researchers were also concerned with the way in which concept mapping has been used to evaluate interdisciplinary knowledge integration and the manner in which instruction can play into that integration ${ }^{15}$. Our method draws heavily from Shallcross's ${ }^{16}$ methodology that targets semi-structured mapping activities by single students in a short time frame. This affords an efficient deployment of concept mapping within a course setting without being disruptive. Due to the exploratory nature of the project and diversity of approaches taken within each section, the authors avoid assessing the concept maps to an exemplar developed by an expert or a singular complexity score. A taxonomy was developed that allows for efficient evaluation of the diversity of concepts present and offers initial statistical evaluation of changes in concept prevalence over time.

The instructor for that section introduced the other researcher and moved aside while one piece of paper $\left(8 \frac{1}{2} \times 11\right.$ ") containing information on and space for developing a map. IRB information was also distributed and explained by the invited researcher. Then the researchers afforded students 15minutes for the activity during the beginning of a class period.

The concept mapping activity was described as comprising "nodes" expressed as words in circles and connections (the links between nodes), a brief set of written instructions and a sample concept map were provided, as well as a short list of connecting phrases. While other scholars have utilized software and more extensive instruction on concept mapping, the approach taken here was deemed appropriate given time and resource constraints ${ }^{17,18}$. Students were instructed to use the back of the paper with the instructors to create their concept maps labeling links was encouraged but not mandated, because the research chose to emphasize concept generation even though this breaks slightly with concept mapping strategies ${ }^{19}$. In this way, the presentation of the exercise carries with it the risks of a low degree of directedness and opportunity for participants to have maximum freedom to construct a map while drawing from prior experiences that could be correlated to broader curriculum elements outside of the course $\mathrm{e}^{20}$.

Researchers reduced these challenges by providing participants with a blank space and minimal guidance. The presenter showed one artifact (either a bicycle or an iPod Classic) to the students and prompted students to create a concept map to the best of their ability ${ }^{21}$. The bicycle was chosen as it is both a classic case example of 'Social Construction of Technology' and might generate recall about the ideas related to prior course. Secondly, the bicycle represents technical innovation, engineering prowess, alternative transportation, environmental sustainability, user demands, privilege, or leisure. The iPod is a smaller object that is encased in a 'Black Box', which is another key concept from STS. The iPod could resemble innovation, planned obsolescence, e-waste, entrepreneurship, patents, globalization, user centered design, or a host of technical elements. The object remained in view for the duration of the exercise. 
The study collected data at three intervals during the academic year on the very first day of the fall semester in August 2015, the final day of the fall semester in December, and a third sample was collected on the final day of classes in May 2016.

\subsection{Coding and Data Analysis}

Coding the concept maps most closely follows Segalis, Ferrer-Balas, and Mulder ${ }^{22}$ and Shallcross ${ }^{16}$ who both evaluated student learning in courses where no 'right' answer was pre-determined. The codes were also aligned with criteria 3 and 5 issued by ABET in the EC 2000 and the revised criteria, see the right-hand side of Table 2. Coding the concept maps using these categories allows for statistical evaluation described subsequently. This initial research does not attempt to create a single score of quality or comprehensiveness, but rather uses categorical scoring so as to leave open comparison to the EC 2000 criteria and tracking concepts prevalence over time ${ }^{14}$. Table 2 lists coding taxonomies from previous studies and the comparable taxonomy used in this study and relevant ABET criteria. It should be noted that the table provides single ABET linkages despite obvious overlap in related codes. 
Table 2. Taxonomy comparisons of concept map categories and examples. Codes employed in this research are aligned (approximately) with previous research. Note: Codes noted on concept maps by researchers are in parenthesis.

\begin{tabular}{|c|c|c|c|}
\hline Segalás et al. ${ }^{22}$ & Shallcross ${ }^{16}$ & Code Employed & ABET EC 2000 Criteria \\
\hline Environment & Environmental & $\begin{array}{l}\text { Nature, Environment, Ecology } \\
\text { (N) }\end{array}$ & 3J: a knowledge of contemporary issues \\
\hline Social impact & \multirow{2}{*}{$\begin{array}{l}\text { Social impacts and } \\
\text { values }\end{array}$} & Social outcomes $(\mathbf{S} \emptyset)$ & $\begin{array}{l}\text { 3H: the broad education necessary to understand the impact of engineering } \\
\text { solutions in a global, economic, environmental, and societal context }\end{array}$ \\
\hline Values & & Ethics/values (E/V) & 3F: an understanding of professional and ethical responsibility \\
\hline Resource scarcity & Resource Scarcity & Materiality (M) & 3E: an ability to identify, formulate, and solve engineering problems \\
\hline $\begin{array}{l}\text { Future Generations } \\
\quad \text { (temporal) }\end{array}$ & \multirow{2}{*}{$\begin{array}{l}\text { Inter- Intra- } \\
\text { generational equity }\end{array}$} & $\begin{array}{l}\text { History, future or temporality } \\
\text { (H) }\end{array}$ & $\begin{array}{l}\text { 3C: an ability to design a system, component, or process to meet desired needs } \\
\text { within realistic constraints }\end{array}$ \\
\hline $\begin{array}{l}\text { Imbalances } \\
\text { (spatial) }\end{array}$ & & Locality (L) & $\begin{array}{l}\text { 3H: the broad education necessary to understand the impact of engineering } \\
\text { solutions in a global, economic, environmental, and societal context }\end{array}$ \\
\hline \multirow{2}{*}{ Technology } & \multirow{2}{*}{ Technology } & Technoscience (T) & 3E: an ability to identify, formulate, and solve engineering problems \\
\hline & & Technical outcomes (TØ) & 3E: an ability to identify, formulate, and solve engineering problems \\
\hline Economy & Economy & Economics (ECON) & $\begin{array}{l}\text { 3H: the broad education necessary to understand the impact of engineering } \\
\text { solutions in a global, economic, environmental, and societal context }\end{array}$ \\
\hline $\begin{array}{l}\text { Actors and } \\
\text { Stakeholders }\end{array}$ & $\begin{array}{l}\text { Actors and } \\
\text { Stakeholders }\end{array}$ & $\begin{array}{l}\text { Social Groups/Users/ non-users } \\
\text { (SU) }\end{array}$ & $\begin{array}{l}\text { 3H: the broad education necessary to understand the impact of engineering } \\
\text { solutions in a global, economic, environmental, and societal context }\end{array}$ \\
\hline Education & Education & excluded & excluded \\
\hline--- & --- & STS concepts (STS) & $\begin{array}{l}\text { 3H: the broad education necessary to understand the impact of engineering } \\
\text { solutions in a global, economic, environmental, and societal context }\end{array}$ \\
\hline--- & --- & Policy/Politics/ Regulation (P) & 3J: a knowledge of contemporary issues \\
\hline
\end{tabular}


The taxonomy most closely matches Segalás et al ${ }^{22}$ with a few exceptions. Outside of semantic differences in the language used more commonly by STS researchers, the following codes were employed in this study:

- Technology is divided between Technoscience [T], e.g. drivetrain, as well as Technical Outcomes [TØ], e.g. less resources needed or $\mathrm{CO}_{2}$ emissions. This allows our analysis to differentiate between portrayals of technologies and actions that give rise to social and/or technical outcomes. For our case we used technoscience as a helpful shorthand for coupled science and technology activities, see Latour ${ }^{23}$ for a more a complex discussion of the term.

- Education was excluded as a category, since a review of the pilot study concept maps revealed no instances of nodes that expressed education directly.

- We added a code for Policy, Politics and Regulation [P], e.g. surveillance or privacy regulations.

- We added a code for Science and Technology Studies [STS], e.g. technological moment, to capture instances in which jargon from the field of STS was expressed directly.

The following provides explanations and examples of the how the codes employed in this study slightly differ from Segalás et al. ${ }^{22}$

- Environment has been renamed as Nature, Environment, Ecology [N], e.g. Habitat and Water.

- Normative claims or attribution of value-laden ideas to groups or design decision is listed as Ethics/Values [E], e.g. close-knit communities and safety.

- Effects on society were coded as Social Outcome [SO], e.g. exercise and piracy. In the case of challenging concepts, such as "close-knit communities", we reference back to placement of the node and its connections and direction of the arrows to categorize it as an ethic/value or social outcome.

- Resource Scarcity, a core concept in sustainability, but one not represented formally in the curriculum under study, is replaced by Materiality [M], e.g. pedals and weight. This decision stemmed from the pilot study, which demonstrated that participants expressed material resources as components rather than an issue of scarcity. All nodes that would have fallen into resource scarcity would be encompassed by Materiality.

- Slight differences in language occurs with Generational Equity and Imbalances, again due to the issue of sustainability course material. The intent is the same in use of History/Temporality [H], e.g. Utopian society and historical trends, and Locality [L], e.g. parks and schools.

- Student's expressions of business, finance, and other economic concepts were captured with the code Economics [E], e.g. profit.

- Actors and Stakeholders was relabeled as Social Groups and Users [SU], e.g. green movement and Steve Jobs.

We acknowledge that, as with all coding schema, it does not represent of all possible categories. The difference in this coding scheme from Segalás et al. ${ }^{22}$ is due to their work focused on a well- 
structured course on sustainability compared to the less-structured, open-ended courses under evaluation.

\subsection{Data Analysis}

All student-participants were assigned a random number and concept maps were rendered anonymous by removing names and adding the designated number and a letter $(\mathrm{A}, \mathrm{B}$, or $\mathrm{C})$ that corresponded to T0, T1, or T2. Researchers analyzed all the concept maps after the conclusion of the spring semester in the summer of 2016 and only after they were rendered anonymous to reduce the potential for researcher bias. The concept maps were coded by the two researchers and an undergraduate researcher supported the coding efforts and completed the data entry into a database. One faculty researcher verified the undergraduates work as quality control. Coding the initial 129 initial maps (T0) took longer, since it was the first use of the coding scheme and took approximately 8 hours with the finalized coding schema and each concept map took approximately 5-7 minutes. Subsequent coding of the T1 and T2 maps took only 2-3 minutes was performed by an undergraduate researcher after a short training session and amounted to 40 hours of work to code and enter the data. One faculty researcher verified the undergraduate's work and rectified any discrepancies or missing codes.

Each concept map was coded and counts were taken for each coded concept, following the taxonomy in Table 2. Two 45-minute focus groups clarified the researcher's interpretation of the concept maps with input from 7 of the 79 participants reported in this paper $(\sim 10 \%)$. The focus group offered participants and researchers an opportunity to reflect upon the experience and included a basic debriefing on the course along with a review of the pre- and post-tests completed by the students. The focus group helped validate and refine the experimental design and coding procedures. Students were presented with copies of their concept maps (T0, T1, and T2) and asked to compare and contrast the maps according to several structured and semi-open questions. The focus group questions entailed looking at the first and second concept maps and walking through the following questions: How has your understanding of the connect between the social and technical changed, where is there evidence of this on the maps, how would you describe the difference between the pre- and post- maps? They were also asked to use an earlier version of the coding scheme to 'score' their concept maps with only the briefest description of each code. The researchers then compared the codes provided by the students and those defined by the research team. This activity offered perspective on student portrayals of what they were attempting to convey in the nodes as well as explanatory data for the influence of context on the process of concept mapping.

Data gathered at the onset of the course (T0) was compared to the end of the first semester (T1) and end of the full academic year (T2). The methodology allows for tracking single participants concept maps over time and was analyzed with a paired t-test to assess whether there were statistically significant differences in the presentation of each code category between mapping activities. Paired t-tests were run on each individual category from the taxonomy. Two aggregate groups were also used to evaluate learning in technical and non-technical areas as a whole. Materiality (M) and Technoscience (T) and Technical Outcomes (TØ) were combined for analysis (MT+TØ) for technical expressions and every other code combined as All Social 
(ALLSo) an aggregation of all non-technical elements including, N, Sø, E/V, H, L, ECON, SU, STS, and P. Ratios between MT+TØ and ALLSoc were explored to understand the relative emphasis on technical vs. non-technical nodes within the concept maps. Ratios between MT+TØ and ALLSoc were analyzed between T0-T1; T0-T2, and T1-T2.

\subsection{Findings}

Concept maps are a reliable means to capture knowledge acquisition over time (course duration) and the outcomes can be linked to ABET criteria. The results that follow address our findings when comparing the initial test (T0) and second (T1) concept maps completed at the end of the fall 2016 semester. A third concept mapping exercise was performed on the final day of the spring semester, but is discussed in the section 4.3 regarding methodical evaluation, since the student-participants did not take the activity seriously (it was there last class in their college experience). The structure of this section includes findings on: baseline knowledge and acquisition, translating concepts to ABET criteria, and finally an evaluation of the concept mapping method itself.

\subsection{Findings: Mapping Knowledge Baselines and Acquisition over Time}

The concept maps offer clear insights about knowledge acquisition from the start of the course to the end. As an example, Figure 1 shows a set of concept maps from Participant 115. The maps show a diversity of nodes that are coded for Nature [N], History [H], and Politics [P], as well as Materiality $[\mathrm{M}]$ and Technoscience [T]. Between the first and second concept mapping exercise the student's work showed an increased quantity and diversity of nodes and connections. T1 shows a greater diversity of ideas that range from design principles, multiple industries and scientific disciplines, specific technical applications, and value statements. While both T0 and T1 have connections that indicate two-way interaction, the second map (T1) has multiple feedback loops and more levels of hierarchy, indicating how this specific artifact is entangled in a complex webs of techno-social relationships. 
Figure 1. Single Participant example pairing of T0 and T1.

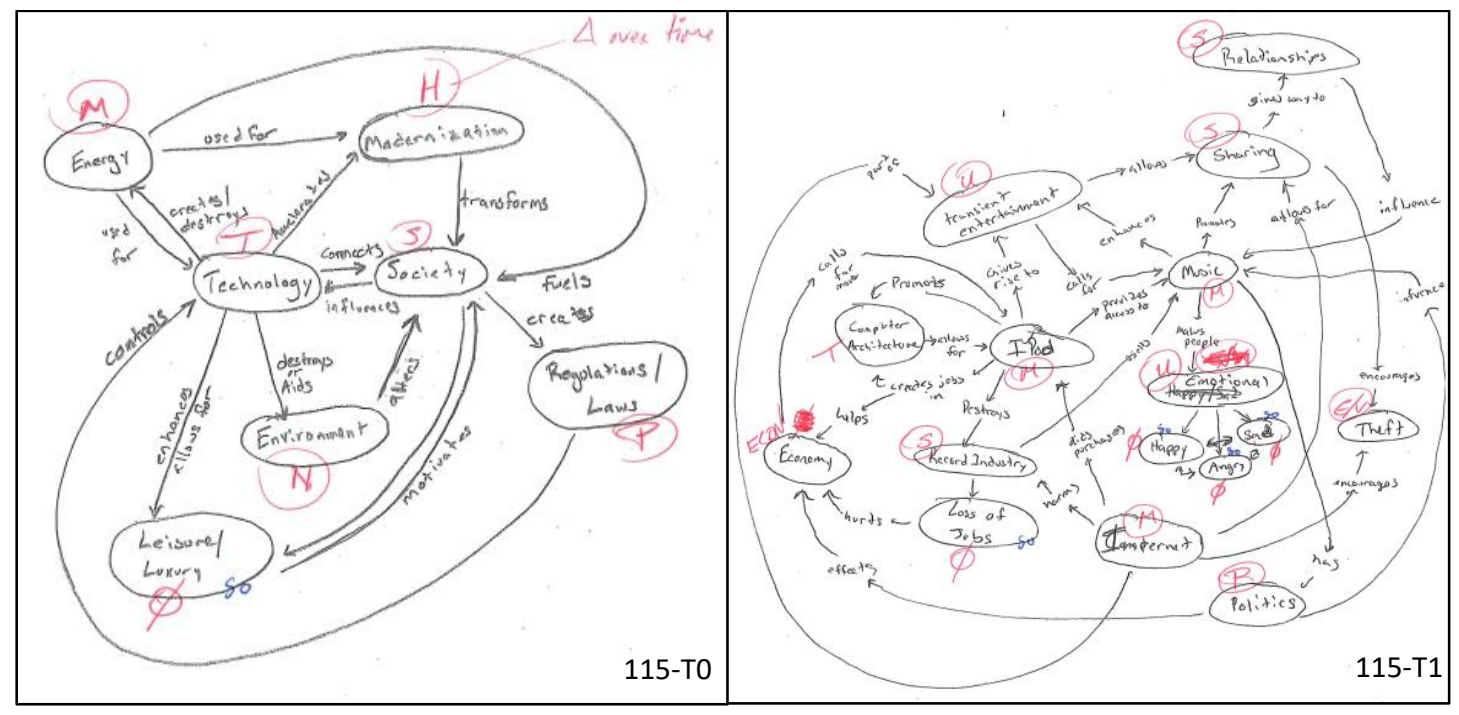

As expected, students also came into STS4500 with far more than knowledge about the technical characteristics of engineering. Figure 2 illustrates the difference in the 'starting point' for two different students. The map on the left created by Participant 125 presents a simplified, highly linear version of solving problems that proceeds from problem definition, research, evaluating options, and considering consequences. Whereas, the map on the right created by Participant 80 shows complexity in how the iPod overlaps many non-technical domains, and also showcases specific knowledge gained from prior courses. In this case, student 80 had taken an elective STS course on the Societal Implications of Nanotechnology (STS 3110).

Even when students may have misunderstood ideas from prior classes there is an acknowledgement that technological change does not occur in a vacuum nor does it drive society in some determined way. For example, Participant 77's pre-map (not shown) includes the term "technological determinism" as a node linked to "design", "unintended consequences", and "ethical decision making" and a side note that states "I do not subscribe wholesale to this theory, but some professors in the past have treated this as doctrine." It should be noted that technological determinism as an argument for what primarily drives social change is critiqued by STS scholars and does not retain theoretical value without juxtaposition with non-technical elements. In other words, the nuance of prior course material was lost but nascent knowledge has still been retained. In another example of reference to prior course experience, Participant 93's pre-map (T0), which is not shown includes only bike components and then draws a "black box" described as "bicycle" around all the parts. This would indicate little integration of previous course work not only for the simplistic breakdown of bicycle without any consideration for science or social as encouraged by the prompt, but the very practice of black boxing technology is treated as the very thing to avoid throughout STS scholarship. The above examples suggest the curriculum has influenced participants to include a number of MT and non-MT nodes. Of the 78 participants evaluated, only two T0 maps and one T1 map have no social codes. 
Figure 2. Two different participants with linear and non-linear concept mapping.

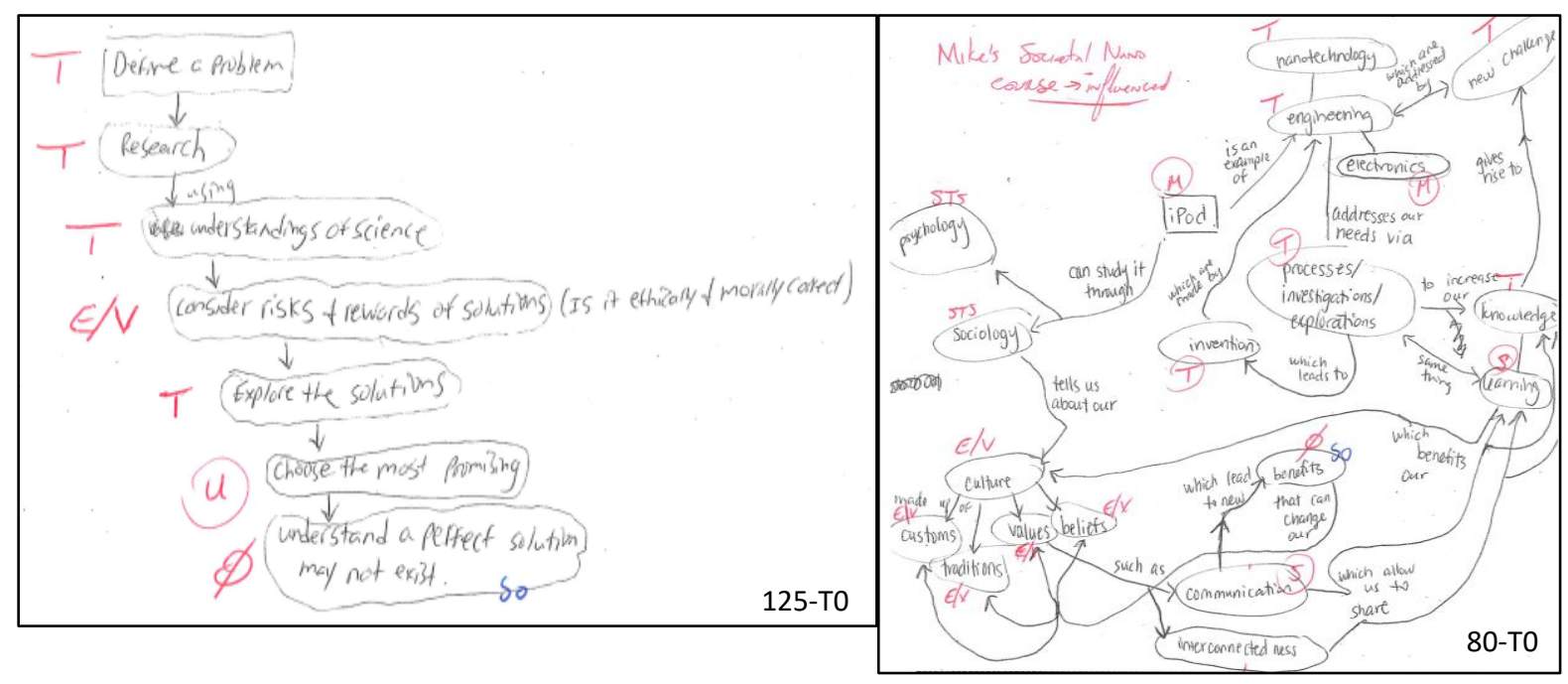

The average student showed a marked increase in knowledge acquisition. Figure 3 shows the aggregated code counts for all participants grouped as technical (MT+TØ) and social codes (AllSoc). Within T0 there is nearly an even ratio between MT-T $\varnothing$ and AllSoc. As a simple measure, this indicates that students encounter the social dimensions of engineering in their prior coursework and incorporate them into the concept maps. Students are able to express a diverse representation of an artifact without formal training in the method of concept mapping and minimal encouragement from the prompt. As such, this activity performs the task of delineating baseline knowledge that students have coming into the course for later comparison as well as indicator of the curriculum impact on student learning. In the T1 maps there is a marked increase in the total quantity of MT-TØ and AllSoc codes, as well as a shift in the ratio with AllSoc outweighing MT-TØ.

Figure 3. Aggregated code counts of Materiality, Technical, and Technical Outcomes alongside all Social Codes for each Test.

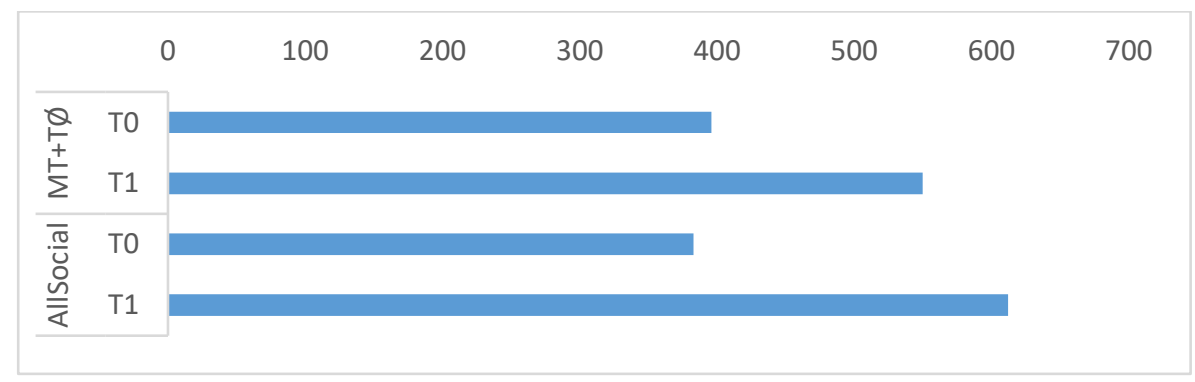

Disaggregating the different social codes shows significant changes from T0 to T1 in several categories as increases and decrease (see Figure 4 for counts and Table 1 for statistical 
significance). The greatest increase is observed in social and user groups ( $\mathrm{S} / \mathrm{U})$ and the outcomes and impacts to these groups (SØ).

Figure 4. Total Count of Codes for T0 and T1.

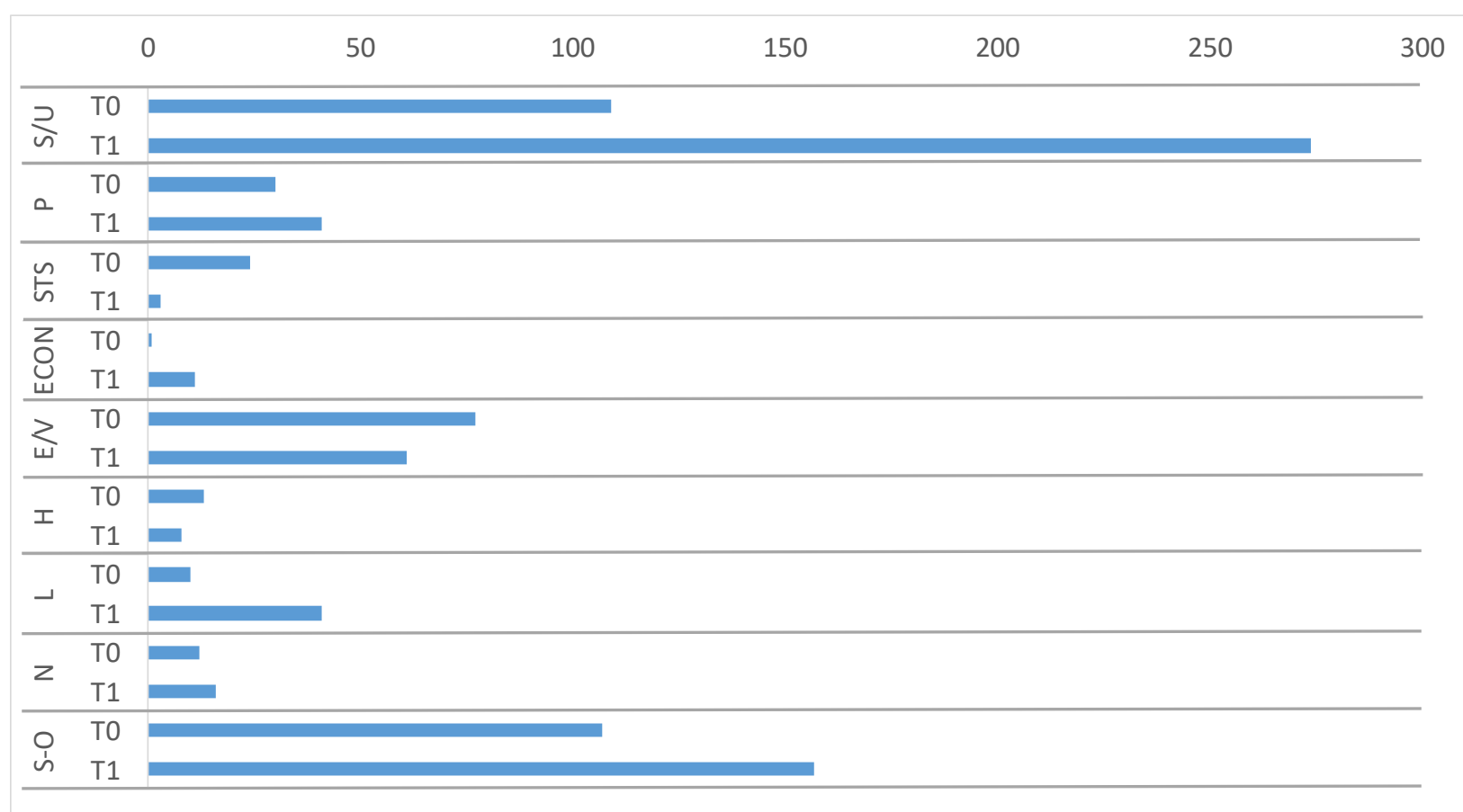

The increase in both technical and social counts is attributed to:

a. comfort with the process of developing concept maps,

b. greater appreciation for the variability of social context,

c. a more sophisticated perception of technological artifacts as embedded in overlapping technological systems, and

d. directed study during the course on the built environmental and technical artifacts as hybrids of society and technology.

The number of concepts derived from STS courses and drops significantly over the course period. Location and localizing groups and technologies as well as Economics shows an increase over time. All other social codes are not significant. Subsequent sections delve more deeply into understanding the shifts in code counts deriving from student participation in the course, life experiences, and concept mapping methodology.

Table 1. Paired t-test results between T0 and T1 associated with related ABET criteria. Significant changes between T0 and T1 have black highlighting. Final column includes alignment with EC 2000 criteria 3 .

\begin{tabular}{|l|c|l|}
\hline \multicolumn{1}{|c|}{ Coded Category } & Sig. (2-tailed) & ABET Related Criteria \\
\hline M0 - M1 & .001 & 3E: Identify and solve engineering problems \\
\hline T0 - T1 & .400 & 3H: Understand impact of engineering solutions \\
\hline SU0 - SU1 & .000 & 3H: Understand impact of engineering solutions \\
\hline P0 - P1 & .223 & 3J: Knowledge of contemporary issues
\end{tabular}




\begin{tabular}{|l|l|l|}
\hline STS0 - STS1 & .001 & 3H: Understand impact of engineering solutions \\
ECON0 - ECON1 & .017 & 3J: Knowledge of contemporary issues \\
\hline EV0 - EV1 & .412 & 3F: Understand professional and ethical responsibility \\
\hline H0 - H1 & .002 & 3C: Design a system to meet desired needs within constraints \\
\hline L0 - L1 & .550 & 3C: Design a system to meet desired needs within constraints \\
\hline N0 - N1 & .096 & 3J: Knowledge of contemporary issues \\
\hline SØ0 - SØ1 & .000 & 3H: Understand impact of engineering solutions \\
\hline TØ0 - TØ1 & .001 & 3E: Identify and solve engineering problems \\
\hline MTTØ0 - MTTØ1 & .000 & 3E: Identify and solve engineering problems \\
\hline AllSocialØ0 - & .001 & $\begin{array}{l}\text { 3E: Identify and solve engineering problems; 3F: Understand } \\
\text { professional and ethical responsibility; 3H: Understand } \\
\text { AllSocialØ1 }\end{array}$ \\
& & $\begin{array}{l}\text { impact of engineering solutions; 3J: Knowledge of } \\
\text { contemporary issues }\end{array}$ \\
\hline
\end{tabular}

\subsection{Findings: Translating Concept Maps to ABET EC2000}

The concept map data offers a promising means to evaluate student outcomes in relation to the ABET EC2000 evaluation accreditation (see Table 1). for a paired t-test between testing periods coupled with ABET criteria. The T0 maps are useful for capturing a single moment of student knowledge in relation to ABET criteria. When T0 is coupled with T1 the data suggests "improvement" and further longitudinal data would allow for measures of "retainment". Materiality, Social and User groups, Economics, Locality, and Technical Outcomes all show significant increase from T0 to T1 concept maps. As a quick approximation, four of the five ABET criteria under consideration in this paper are considered successfully integrated into the STS4500 course (3C, 3E, 3H, and 3J), while 3F: "Understanding professional and ethical responsibility" does not show statistically significant improvement in this time period. This is not surprising as the spring course (STS4600) more directly targets ethics and professionalism. Unfortunately, the timing of the T2 (on the last day of the spring semester) did not adequately capture student learning and is discussed below.

\subsection{Findings: Timing affects the quality of student work}

Procedures for deploying the concept maps matter in several regards. Instructions given at the time of presenting the concept mapping exercise and the timing of the exercise in relation to externalities of the semester are two primary concerns. For instance, Figure 5 highlights an example where the student was invested in creating a complex map during the T1 period, but was not given enough reinforcement to start with the given artifact they encountered in T0. Rather than an Ipod or bike, they chose to focus on chocolate as a product, global commodity, and ethically challenging food resource. The timing of $\mathrm{T} 2$ on the final day of the spring semester did not capture robust data and the researchers observed drop-offs in all categories. Participants in the focus group explained that by the final day of classes in the final year of school they were "checked out" when the researchers asked them to complete the final exercise (T2). 
Figure 5. Representation of non-compliance.

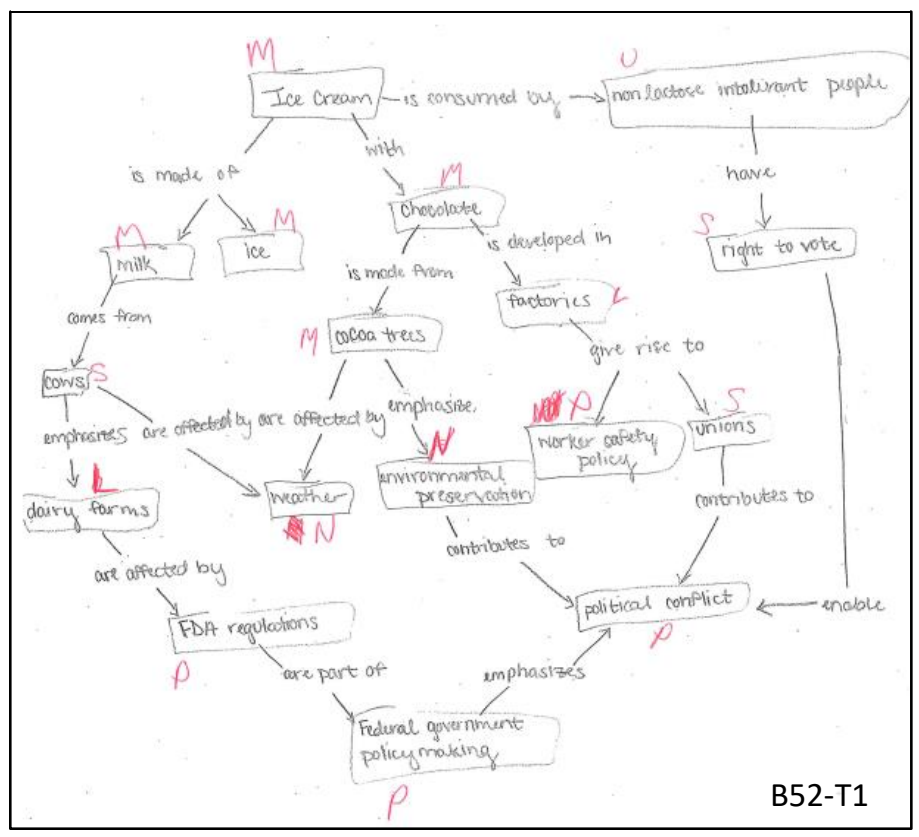

\subsection{Discussion}

This small-scale, exploratory research project with $4^{\text {th }}$ year engineering students at the UVA offers promising results that warrant further exploration. While, there is no 'perfect' answer for demonstrating the social context within which an artifact exists, the instrument captures student learning outcomes overtime that can be coded for key concepts associated with both the course's objectives and ABET EC 2000 criteria. The aggregate scores offered in Figure 2, showed broad knowledge acquisition and the results from detailed coding schema in Figure 3 offers a nuanced look at the knowledge acquired during the course sequence and may offer insights on differences between course instructors. This approach offers an intriguing diagnostic tool for curriculum evaluation, reform or pedagogical shifts. This technique also offers a means to align studentlearning outcomes with the ABET EC2000 criteria.

Previous studies have utilized the t-test and thus we followed in that manner as a starting point. It must be stated that our data does not follow a normalized two-tail distribution. However, given the limited sample size and exploratory nature of this research we were comfortable presenting results from this analysis despite the lack of a normalized distribution caused by a small number of outliers. The concept mapping exercise itself generates outliers, since some people simply work faster than others. Prior studies, for example, Borrego et al ${ }^{15}$ and Shallcross ${ }^{16}$ addressed the outlier problem by using a ranking system that manipulates the data to fit a normalized distribution prior to statistical analysis. However, with or intent to explore the capabilities of concept mappings and to encourage a discussion of how these activities could be leveraged for more than a mark of complexity we have presented the data in a variety of formats. 
The semi-structured coding approach employed in this study allows for the researchers to "unpack" knowledge acquisition among different categories that represented key themes in the course. This was validated by the participants in the focus group and gives us confidence in the coding structure. The engineering students were able to express socio-technical complexity through a rather simple tool that depends on paper and pencil, rather than relying upon more complicated software programs ${ }^{16,22}$. The test was administered in 15-minutes during class time and once the coding schema was solidified, the scoring took 2-5 minutes depending on the complexity of the concept maps. For a larger evaluation study, a representative sample of the total population could be randomly selected and scored for evaluation purposes, rather than scoring every concept map.

While the results offer promise, there are numerous avenues for further investigation and improvement. One avenue is related to the instructor's influence through inter-instructor comparison, as well as differences between sections taught by the same instructor (intrainstructor comparisons). The selection of the artifact presented as the prompt may influence the results, but there was insufficient material at this time to draw any conclusions. Certainly, the timing of T2 (the last day of the student's final semester) was a design flaw. Indicators of "continuous improvement" and tertiary testing for long-term retention are lacking in this study as this process would need to be conducted for several years starting with students first coming into the University. The influence of prior courses are not fully accounted for, yet were noted by participants in the focus group as significantly influencing the T0 concept maps. This motivates our continued efforts and addressing those issues will support a more robust testing and evaluation method.

\subsection{Conclusion}

While further refinement is needed, this approach should be considered as a useful tool for instructors and administrators alike for future ABET assessments. This simple tool needs to be considered alongside other assessment tools, such as summative research reports and portfolios. This holds particularly true for documenting continuous improvement at the individual, course, and institutional level. We are not suggesting this is the one and only way to do this, yet this approach does complement other assessment techniques. Nonetheless, as engineering schools across the country prepare for their next assessment, we strongly advocate for the community to create a "catalog" of best practices that can be reviewed and shared among peer institutions, such that no one is forced to 'reinvent the wheel' when others have tried, failed, and improved their assessment techniques. We would encourage leading organizations, such as the NAE or the NSF's Engineering Education directorate, to facilitate a platform for knowledge sharing and peer-review to improve the quality of assessment techniques for non-technical criteria that build in programmatic and administrative efficiencies, rather than creating redundant efforts that may still yield ineffective assessment results.

\section{References}


1. Paustenbach, D. J. Bhopal, Asbestos, and Love Canal ... How They Should Affect Engineering Education. IEEE Technol. Soc. Mag. 6, 9-15 (1987).

2. ABET. Sustaining the Change: a Follow-up Report to the Vision for Change. 14 (ABET, Inc., 2004).

3. Shuman, L. J., Besterfield-Sacre, M. \& McGourty, J. The ABET 'Professional Skills' — Can They Be Taught? Can They Be Assessed? J. Eng. Educ. 94, 41-55 (2005).

4. Benderley, B. L. Standards Practice: Proposed Changes to Accreditation Criteria Have Touched off a Tempest in the Engineering Community. ASEE Prism 25, 34-37 (2016).

5. Rogers, G. Assessment: Choosing Assessment Methods. (2015). Available at: http://www.abet.org/blog/webinars/assessment-choosing-assessment-methods/ (Accessed: 14th November 2016)

6. Olds, B. M., Moskal, B. M. \& Miller, R. L. Assessment in Engineering Education: Evolution, Approaches and Future Collaborations. J. Eng. Educ. 94, 13-25 (2005).

7. Shryock, K. \& Reed, H. ABET accreditation: Best practices for assessment. in Proceeding of the Annual American Society of Engineering Education Conference (2009).

8. Rogers, G. Death by Assessment: How Much Data Are Too Much? Communications Link (2002). Available at: http://www.abet.org/wp-content/uploads/2015/04/death-byassessment.pdf. (Accessed: 2nd November 2016)

9. Nesbit, J. C. \& Adesope, O. O. Learning with concept and knowledge maps: A metaanalysis. Rev. Educ. Res. 76, 413-448 (2006).

10. National Academy of Engineering. Infusing Ethics into the Development of Engineers: Exemplary Education Activities and Programs. (National Academy Press, 2016).

11. Derbentseva, N., Safayeni, F. \& Cañas, A., J. Concept maps: Experiments on dynamic thinking. J. Res. Sci. Teach. 44, 448-465 (2007).

12. Kinchin, I. M. Concept Mapping as a Learning Tool in Higher Education: A Critical Analysis of Recent Reviews. J. Contin. High. Educ. 62, 39-49 (2014).

13. DeFranco, J. F., Jablokow, K., Piovoso, M. J. \& Richmond, S. S. Objectively Assessing Concept Maps for Knowledge Integration. Int. J. Eng. Educ. 31, 1288-1298 (2015).

14. Watson, M. K., Pelkey, J., Noyes, C. R. \& Rodgers, M. O. Assessing Conceptual Knowledge Using Three Concept Map Scoring Methods. J. Eng. Educ. 105, 118-146 (2016).

15. Borrego, M., Newswander, C. B., McNair, L. D., McGinnis, S. \& Paretti, M. C. Using concept maps to assess interdisciplinary integration of green engineering knowledge. $A d v$. Eng. Educ. 1, 1-26 (2009).

16. Shallcross, D. C. Concept Maps for Evaluating Learning of Sustainable Development. J. Educ. Sustain. Dev. 10, 160-177 (2016).

17. McClure, J. R., Sonak, B. \& Suen, H. K. Concept map assessment of classroom learning: Reliability, validity, and logistical practicality. J. Res. Sci. Teach. 36, 475-492 (1999).

18. Muryanto, S. Concept Mapping: An Interesting and Useful Learning Tool for Chemical Engineering Laboratories. Int. J. Eng. Educ. 22, 979-985 (2006).

19. Novak, J. D. Learning, Creating, and Using Knowledge: Concept maps as facilitative tools in schools and corporations. J. E-Learn. Knowl. Soc. 6, 21-30 (2010).

20. Ruiz-Primo, M. A. Examining concept maps as an assessment tool. in Proceedings of the First International Conference on Concept Mapping 1, 555-562 (2004).

21. Trowbridge, J. E. \& Wandersee, J. H. in Teaching Science for Understanding: A Human Constructivist View (eds. Mintzes, J. J., Wandersee, J. H. \& Novak, J. D.) 95-128 (Elsevier Academic Press, 2005). 
22. Segalàs, J., Ferrer-Balas, D. \& Mulder, K. F. Conceptual maps: measuring learning processes of engineering students concerning sustainable development. Eur. J. Eng. Educ. 33, 297-306 (2008).

23. Latour, B. Science in Action: How to Follow Scientists and Engineers through Society. (Harvard University Press, 1988). 